\title{
Marital Stress, Antenatal Anxiety, Social Support, and Postnatal Depression among Nursing Mothers in Ibadan
}

\author{
A. S. Okhakhume (Phd) \\ Department of Psychology \\ University of Ibadan \\ Shide Sunday (M. Sc.) \\ Department of Psychology \\ Benue State University, Makurdi. \\ Angela I. Osuagwu (M. Sc.) \\ Department of Psychology \\ University of Ibadan
}

\begin{abstract}
Postnatal depression is a mental health disorder afflicting between 15-18 percent of new mothers in Nigeria. Depressive symptoms and actual depression affects the psychological and social wellbeing of the affected mothers, their new infants, husbands and family members. Consequently, this study examined the effect of marital stress, antenatal anxiety, and social support on postnatal depression among nursing mothers in Ibadan. The study used an ex-post factor survey research design. A total of 128 nursing mothers $(\mathrm{N}=128 ; \%=98.4)$ were administered questionnaire in Ibadan. The participants' average age was 29.68 years. Results revealed that antenatal anxiety has a significant correlation with postnatal depression $(\mathrm{P}<.05)$. Also, separate social support was found to have an inverse correlation with postnatal depression $(r=.047)$; marital stress has a positive correlation with postnatal depression $(r=.108)$. Also, finding showed that antenatal anxiety has a significant independent influence on postnatal depression $(\beta=230 ; t=2.633 ; P=<.05)$ and there was a joint influence of marital stress, antenatal anxiety and social support on postnatal depression $\left(R^{2}=.070, F=3.128\right.$, $P<.05$ ) with a $7 \%$ variability. Social support mediates the influence of antenatal anxiety on postnatal depression $(r=.239)$ while family structure has a significant independent influence on postnatal depression $(\beta=.266 ; t=2.880 ; \quad P=<.05)$. Psychological interventions and assessment of the independent and joint risk factors that are related to postnatal depression in nursing mothers be undertaken in hospitals with the aim of reducing the overall impact of these risk factors on postnatal mothers.
\end{abstract}

\section{INTRODUCTION}

Throughout the world, scholars have mentioned that, the importance of sound mental health for postnatal mothers cannot be overemphasized; it is germane to their overall wellbeing; that of their new infants and their family members. When a woman with good mental health gives birth to a healthy child, the society and the world at large may be free from future health challenges. However, many postnatal mothers have been found to suffer from depressive symptoms and disorder. Depression accounts for the greatest burden of disease among all mental health problem, and also, it is expected to become the second most prevalent of all general health problems globally by 2020 (Murray and Lopez, 1996; WHO, 2000). Depression is a major public and mental health problem that is supposedly twice as common in women during the childbearing age as it is in men (Stewart, D.et al, 2003). 
Postnatal Depression (PND) as a mental health challenge has gained a lot of attention. There is worldwide evidence that postnatal depression and prevalence figures may vary according to different countries even when the same tool is used to measure the phenomenon (Zubara et al., 2010). Numerous articles over the past 10 years have documented the extent of maternal depression, including postnatal depression which ranges from $15 \%$ of women ( $0^{\prime}$ Hara and Swain, 1996), report has also indicated that the incidence level is much higher than this quoted interval rate (Palo, 2009). Epidemiological studies have reported prevalence rates of postnatal depression in Chinese women as 13.5\% (Lee et al, 2001), Indian women 23\% (Patel et al, 2002), Arab women 15.8\% (Ghubash \& Abou-Selah, 1997), Japanese women 17\% (Yoshida et al, 2001), and Pakistani women 28\% (Rahman et al, 2003). In Africa Countries, prevalence among Zimbabwean women 16\% (Nhiwatiwa et al, 1998), and 34\% in South African women (Cooper et al, 1999). Additionally, in developing countries, studies have shown that the rate of maternal depression is increasing by the day; in Nigeria, it is estimated at $18.6 \%$ (American society for Nutrition, 2009; Abiodun, 2006).

Postnatal depression can be experienced by women in different forms. Postnatal depression is mostly diagnosed when symptoms are severe and have seen to last for two to six weeks after delivery, may even last up to six months and sometimes a year. Most women are affected by mood symptoms in postnatal periods (4-6 weeks after the child birth). In the literature, mothers with postnatal depression describe feeling of loss, such as loss of control (Beck 1992, 1993, Ugarriza 2002, Chan \& Levy 2004) or loss of former identity (Nicolson 1990). Physical changes occur such as the disruption of sleep pattern, and adjustments may be made in daily personal routines. Many women experience self-limited symptoms called postnatal or postpartum blues, mild symptoms of postnatal depression to major depression and postnatal psychosis. The symptoms relevant to baby blues are reported in most of these women which is a mood disturbance and is characterized by mood instability, feeling of unhappiness, feeling of dysphoric, mental confusion and weeping (Kaplan et al, 2009).

Postnatal depression differs from general depression to the perspective of timescale (Evans et al. 2001) and in the context of role transition, the loss of familiarity, loss of control and the need to feel normal (Scrandis 2005). At the other end of the spectrum is postpartum or postnatal psychosis, which is characterized by severely depressed mood, disorganized thinking, delusions and psychotic thoughts, as well as hallucinations. Often its onset is in close proximity to childbirth (Kendell, 1987; Munk - Olsen et al, 2006). According to the DSM-V-TR, peripartum depression sets as a specifier for major depressive episodes (American Psychiatric Association, 2013). This however suggests that postnatal depression has the same diagnostic criteria for major depression except that it occurs during or some weeks after pregnancy.

As a disorder, postnatal depression has a substantial impact on the quality of life and social functioning of the mother. Due to the adverse consequences on the mother, the child and family at large, the importance of early detection and management is widely recommended by clinical personnel. The effects of postnatal depression make it an important condition to diagnose, treat and prevent (Robinson \& Stewart, 2001). Pregnancy and childbirth especially in Africa and Nigeria is known to be a period of joyful occasion for the mother and the family as a whole. It is a time of dynamic change and expectation for many women, however, for some women the postnatal period comes with depressive episodes and/or becomes a precipitant period of major depression. An increasing amount of evidence suggests that, for a relatively large proportion of women, the process of childbearing can trigger serious emotional problems and lead to a disturbing and sad mood (Green et al, 2006). It has been noted that some Nigerian mothers had to stop having more babies because they suffered postnatal depression from previous post pregnancy period (Ayomide, 2015). Culpepper and Jack (1993) recommended 
that comprehensive assessment of antenatal psychosocial risk factors should be integrated into routine medical care.

The International and National Policy documents have suggested that social support is necessary for maternal and infant well-being (Commission on the Family, 1998, WHO, 2005) because it facilitates postnatal women's adaptation to motherhood (Schachman et al. 2004). Research showed that lower levels of social support were related to higher rates of postnatal depression in the postnatal period which is in synchrony with previous studies (0'Hara \& Swain, 1996; Glasser et al. 2000; Inandi et al., 2002;, Surkan et al., 2006;, Ege et al., 2008; Gao et al., 2008). Lack of social support, baby's temperament, fear over the child care, poor marital status and relationship and marital difficulty can cause postnatal depression. mothers in the postnatal period have reported that the support received from their husbands and mothers, both with household chores and infant care, is of significant importance to them (HaggmanLaitila, 2003). Some researchers also agreed that lack of social support, poor marital adjustment can lead to depression in nursing mothers. For instance, Gao, Chan \& Mao, 2009), have confirmed that stress, partner's depression (related to marital stress) and social support are significantly associated with postnatal depression.

Providing support for mothers in infant care in the postnatal period is an important concern for nurses and midwives. Research has shown that social support can facilitate women's transition to motherhood (Logsdon \& Davis, 2003, Warren \& McCarthy, 2007). Owoeye A. O., et al., (2006) established that the risk factors associated with postnatal depression in a group of Nigerian women include; unwanted pregnancy, unemployment and marital conflict. Postnatal depression has negative implications on the mother-child interaction and attachment. Mothers with postnatal depression are often times withdrawn and disengage themselves from activities; it also affects mother-child communication which is important for the child's cognitive development.

Robertson et al., (2004), has found that high levels of antenatal anxiety are a strong predictor of depressive disorder in postnatal mothers. According to Bowlby, (1973), attachment theory, individuals who were unable to establish secure attachment bonds in their early lives, are hypothesized to have higher levels of anxiety in daily-life situations. Consequently, Huizink et al, (2004) has operationalized antenatal anxiety and postnatal depression with general anxiety measures. However, researchers have identified specific antenatal anxiety and postnatal fears and worries such as fear about the baby, fear for labor pain, the integrity of the baby, or changes in personal and marital life (Areskog et al,. 1981; Beck et al., 1980; Elliott et al., 1983; Rizzardo et al., 1985; Sjogren, 1997). According to Raphael-Leff (2005), pregnancy and motherhood are guided with unique maternal emotions, cognitions and behaviours relating to the different trends across individual women. Each of these trends is suggested to have specific psychosocial triggers to antenatal anxiety and postnatal mental and behavioural disturbances.

Socio-demographic variables such as age, marital status, marital dissatisfaction and marital stress, lack of social support, and pregnancy related clinical symptoms like, risk status of pregnancy, previous pregnancy experiences, have been found to be associated with higher levels of anxiety in pregnant women and thereby leading to postnatal depression. (Armstrong and Hutti, 1998; Da Costa et al., 1999; Higgins et al., 1994; Kalil et al., 1993; Levin 191; Mc Veigh and Smith, 2000; Melender, 2002; Melender, 2002; Paarlberg et al., 1999; Saisto and Halmesmaki, 2003; Saisto et al., 2001;). 


\section{STATEMENT OF PROBLEM}

Postnatal depression has been known to have a substantial impact on the quality of life and social functioning of mothers as well as on the cognitive development and emotional stability of their children. The effect of this condition is extended to the family as a whole; it leads to strain in marital relationships due to spousal neglect, marital infidelity and divorce; and in the extreme cases, suicidal ideation is developed among affected mothers (Stewart et al., 2003; Adewuya et al., 2005; Owoeye, et al., 2006). Consequently, it increases poor public mental health which leads to poor human and psychological development.

Literature has showed that marital stress is closely related to depression (Wang \& Patten, 2001; Tennant, 2001). Whisman \& Kaiser, (2008), argue that marital functioning is mostly associated with the course, onset and treatment of depression. Marital stress depicts the absence of marital functioning. When marital discord exists among postnatal mothers and their spouses, it increases the chances of depressive symptoms and disorder after birth (Owoeye et al., 2006; O'Hara and Swain, 1996). In Ibadan metropolis, when there is marital stress due to infidelity, lack of financial support and neglect, some postnatal mothers may develop postnatal depressive symptoms and in extreme cases, postnatal depression. As a result, their children are subjected to possible abandonment, and they become insensitive to people including family members.

Antenatal risk factors have been seen to have a great association with postnatal depression. Due to neglect, marital discord and financial lack, pregnant women in Ibadan sometimes suffer from pregnancy anxiety. The antenatal anxiety is manifested in postnatal fears and worries such as fear about the baby, fear for labor pain and the integrity of the baby (Sjogren, 1997) and these may cause depressive symptoms during postnatal period. Robertson et al. (2004), has found that high levels of antenatal anxiety are a strong predictor of depressive disorder in postnatal mothers. Therefore, the persistence of depression symptoms in pregnancy due to antennal anxiety exposes new mothers to postnatal depression.

Lee et al, (2004) found that conflict with mother-in-law, marital dissatisfaction, past depression, and antenatal depressive symptoms are independent antenatal risk factors for postnatal depression. The poor mother and daughter-in-law relationship is a risk factor associated with postnatal depression. A postnatal mother could receive support from her mother-in-law if the mother-in-law visits the home and stay for a period, usually months. The unrelenting pressure and great demands that some mother-in-laws put on their postnatal daughter-in-law sometimes trigger the underlying depression. Increased contact with such mother-in-law leads to conflict between the women, and sometimes it worsens if there is no support also from the husband thereby leading to the onset of postnatal depression.

It was therefore hypothesized that:

i. There will be a significant correlation among marital stress, antenatal anxiety, social support and postnatal depression among nursing mothers in Ibadan.

ii. Marital stress, antenatal anxiety, social support will have significant joint and independent influence on postnatal depression among nursing mothers in Ibadan.

iii. Social support will significantly mediate the influence of marital stress and an antenatal anxiety on postnatal depression among nursing mothers in Ibadan.

iv. Age, educational level, marital status, family structure, and job status will have significant joint and independent influence on postnatal depression among nursing mothers in Ibadan? 


\section{Design}

\section{METHODS}

The study adopted a survey research method, which specifically utilized the Ex-Post Facto design. The design was found appropriate because the researchers were not involved in the manipulation of any variable(s) of interest. The independent variables in this study were marital stress, antenatal anxiety, and social support. The three independent variables are on the scale as well as their sub-scales; they were categorized into high and low, using the mean score as the dichotomous norm. The dependent variable for the study was postnatal depression, which was measured on interval scale. The study, which basically involves questionnaire administration, was conducted in four hospitals in which postnatal mothers come for postnatal clinics and check up located in Ibadan were visited. These hospitals and health centers were Ibadan Central Hospital (ICH), Old-Ife Road, Ibadan; Agbowo community Maternity Health Center in Agbowo, Ibadan; Maternity Centre, Jaja Clinic, University of Ibadan; Idi-Ogungun Maternity Health Center, Agodi Gate, Ibadan, in Oyo State. The aforementioned hospitals and health centers were selected purposively because they have regular postnatal clinics and are located in different housing districts in city of Ibadan. Ethical and administrative approval was obtained for the data collection in each of the hospital/health centers. Ethical and administrative approval was obtained for the data collection in each of these hospital/health centers. Respondents' approval was also obtained prior to administering the research instrument on them. A total of 128 nursing mothers took part in the study.

\section{Measures/Instruments}

The current study utilized the structured questionnaire for data collection; made up of five (5) sections A, B, C, D and E.

Section A of the research instrument obtained information on mothers' socio-demographic data, such as age, religion, ethnic group, educational level, marital status, family structure, employment status, how old the baby is now and what number the baby is in terms of birth order.

Section B of the research questionnaire assessed the level of depression in postnatal mothers. This was measured with a 10-item Edinburgh Postnatal Depression Scale (EPDS) developed by Kendel et al in Edinburgh Scotland. Each items of the 10-items has a possible 4(four) responses which the women are asked to underline according to how they feel in the past 7 days. The EPDS scores ranges from 0-30 and with varying levels of sensitivity and specificity depending on where the cut-off score lies. The sensitivity of EPDS is known to increase with lower cutoff scores but with low cost of specificity, consequently, the higher the score, the likelihood of a depressive symptom. A score of 13 and above indicates the existence of depression. EPDS is the result from the first major research carried out by Kendel et al for over thirty years ago. It was developed to identify symptoms of depression that are common with childbearing and postnatal mothers; hence, it is not a diagnostic tool. The EPDS is widely used and has been confirmed by a recent review about it high sensitivity which can also be compared with the DSM-III and IV criteria for major depression.

Section C of the research instrument measured anxiety both in the antenatal and postnatal periods, it is called the Perinatal Anxiety Screening Scale (PASS) which was developed and validated by Somerville et al of the Women's Health Care Clinic Unit (WHCCU), Department of Psychological Medicine, Western Australia, 2013. The PASS is a 31-item scale of a 4-point response format ranging from Not at all, sometimes, often to almost always with a weight score of $0,1,2$ and 3 , attached to them respectively. 
Section D of the research instrument measures the social support aspect of the research. The Postpartum Support Questionnaire (PSZ; Longsdon \& McBride, 1989) is a 34-item questionnaire that measures the importance and helpfulness of the support expected during the antenatal or the postnatal period. But in this study, the main focus of the social support is the one received in the postnatal period. The 34 statements include four types of support postnatal mothers needed in the postnatal period which was outlined by Cronenwett (1985b), and based on the work of House (1981). The four categories of support include: (a) emotional, which involves providing empathy, caring, love and trust, (b) material, which involves behaviors that directly help the person in need such as taking care of the person, (c) informational, which involves providing information for the person to deal with problems related to childcare, and (d) comparison, which involves transmission of information for the person to use in evaluating themselves by being someone in a similar situation or having a similar experience. There are 10 (ten) items for emotional support, 10 (ten) items for informational support, 9 (nine) items for material support and 5 (five) items for comparison support.

In the postnatal assessment social support questionnaire, respondents indicates whom they think can provide the help they need from their mother, partner (father of the baby), partner, friend, other family member to no one, and then rate the degree to which the help is important to them on a seven point Likert scale (from not important, N1; to very important, VI) and also the degree of help they anticipate to receive (from no help, $\mathrm{NH}$; to lots of help, LH). With the same set of 34 statements and response scale, respondents rate the importance and actual help they receive after delivery. Scores of items under each type of support are summed up to form scores of subscales for both importance ratings and support scores. Scores for the subscales range from 7 to 70 for emotional support and informational support, 7 to 63 for material support, and 7 to 35 for comparison support. Scores of the four subscales are summed up to form a total postnatal importance score, postnatal anticipated support score, postnatal importance score and postnatal support score and they all range from 34 to 238.

A pilot study was conducted on a total number of 20 participants to test the reliability and validity of the postnatal support scale and the result of the pilot reported valid for the population. Total scale item 34, with a mean score of 107.2188, and standard deviation of 54.83747 and reliable with a Cronbach's Alpha of .964

Section $\mathbf{E}$ of the research questionnaire assessed the stress that couples face in their marriage which was developed by P.F. Omoluabi (1994). The marital stress inventory is to determine the cause of stress among couples and to evaluate their stress reaction. It is a 50 -item inventory, the response format for the scale is structured and ranges from Slight effect, Mild effect, Moderate effect, severe effect, to Very severe effect with a weight score of $1,2,3,4$ and 5 respectively attached to them. The norm for the interpretation of the score is the mean score obtained from the general population, hence, scores higher than the norm indicates the high level of stress. Items rated 4 and 5 indicates the specific cause of stress for the respondent.

The study adopted both the descriptive and inferential statistics. The descriptive statistics was employed to obtain information based on frequency ( $f$ ), percentage (\%), mean (X) and standard deviation (SD) which applies most especially to demographic characteristics of the study participants. The inferential statistics was employed in testing the stated hypothesis. The Pearson Product Moment correlation was used in testing the first research hypothesis which establishes the correlation among marital stress, antenatal anxiety, social support and postnatal depression. Hypothesis two was tested using the multiple regression analysis to establish the joint and independent influence of marital stress, antenatal anxiety, and social 
support on postnatal depression. On the third hypothesis, partial correlation analysis was used to test whether social support will mediate the influence of marital stress and antenatal anxiety on postnatal depression. For hypothesis four, multiple regression analysis was carried out to establish whether age, educational level, marital status, family structure, and job status will have significant joint and independent influence on postnatal depression.

\section{Procedure}

Consent letter for permission for questionnaires administration was submitted to the Offices of the Matron in charge of each hospitals and each of the application letter for permission was attached to each copy of the Research Questionnaire. The application document at the respective hospitals was followed up; and eventually permission was given on time. Three research assistants were employed during the course of questionnaire administration; they helped in the reading of the questions out in the Yoruba language to some participants who could not read on their own.

\section{Demographic characteristics}

\section{RESULTS}

The participants' age ranged between 15 to 45 years; with an average age of 29.68 years, the majority (56.6\%) was Christians while rests (43.4\%) were of the Islamic religion. In terms of their ethnic groups, $78 \%$ were Yoruba, $14.2 \%$ Hausas, and other ethnic groups were $5.5 \%$. Among the respondents, $48.8 \%$ and $31.5 \%$ had attained secondary and tertiary education respectively. Significant majorities (89.1\%) of the women were married; similarly $81.7 \%$ of the families are monogamous. Also, job status indicates that $82.1 \%$ are employed while the age of the babies ranged from one to nine month postnatal.

The first research question was do age, educational level, marital status, family structure, and job status have any significant joint and independent influence on postnatal depression among nursing mothers in Ibadan? To answer this question, a hypothesis was formulated.

\section{Hypothesis 1}

Age, educational level, marital status, family structure, and job status will have significant joint and independent influence on postnatal depression. The hypothesis was tested using standard multiple regression and the result is presented in Table 4.1

Table 4.1 Summary Showing Multiple Regression Analysis of Independent and Joint Influence of Age, Educational Level, Marital Status, Family Structure and Job Status on Postnatal Depression

\begin{tabular}{|lllrrrrrr|}
\hline Dependent & Variables & $\mathrm{R}$ & $\mathrm{R} 2$ & $\mathrm{~F}$ & $\mathrm{P}$ & $\beta$ & $\mathrm{t}$ & Sig \\
\hline Variable & & & & & & & & \\
\hline & Age & & & & & -.092 & -1.030 & n.s \\
\hline & Educational level & & .156 & 4.073 & $\mathrm{P}<.05$ & -.060 & -.574 & n.s \\
\hline Postnatal & Marital status & .395 & & & & .045 & .461 & n.s \\
\hline Depression & Family structure & & & & .266 & 2.880 & $\mathrm{p}<.05$ & \\
\hline & Job status & & & & & .181 & 1.886 & n.s \\
\hline
\end{tabular}

The result presented in Table 4.1 above showed that family structure has a significant independent influence on postnatal depression $(\beta=.266 ; t=2.880 ; \mathrm{P}=<.05)$, meaning that the type of family structure, either monogamy or polygamy has an influence on postnatal 
depression. More so, there was a significant joint influence of age, educational level, marital status, family structure and job status on postnatal depression $\left(\mathrm{R}^{2}=.156, \mathrm{~F}(4,073), \mathrm{P}<.05\right)$ with $15.6 \%$ explanation of the variability of the dependent variable. Therefore, hypothesis one was partially supported.

\section{Hypothesis 2}

Social support will mediate the influence of marital stress and antenatal anxiety on postnatal depression. The hypothesis was tested using partial correlation analysis and the result is presented in Table 4.2 below.

Table 4.2 Summaries showing partial Correlation Relationship between Social Support, Marital Stress, Antenatal anxiety, and Postnatal Depression.

\begin{tabular}{|c|c|c|c|c|c|c|c|c|c|c|c|c|c|}
\hline Contr & Variable & Mean & & Std & & $\begin{array}{l}\text { PND } \\
\end{array}$ & & MS & & $\overline{\mathrm{AA}}$ & & \multicolumn{2}{|l|}{$\overline{\mathrm{SS}}$} \\
\hline \multirow{4}{*}{ None } & -.047 & \multicolumn{2}{|l|}{ PND. } & \multicolumn{2}{|l|}{9.7813} & \multicolumn{2}{|l|}{5.454} & \multicolumn{2}{|l|}{1} & \multicolumn{2}{|l|}{.108} & \multicolumn{2}{|l|}{$.242^{* *}$} \\
\hline & $.291^{* *}$ & \multicolumn{2}{|l|}{ MS. } & \multicolumn{2}{|l|}{121.7} & \multicolumn{2}{|l|}{46.654} & \multicolumn{2}{|l|}{.108} & \multicolumn{2}{|l|}{1} & \multicolumn{2}{|l|}{.062} \\
\hline & -.096 & \multicolumn{2}{|l|}{ AA. } & \multicolumn{2}{|l|}{25.734} & \multicolumn{2}{|l|}{11.211} & \multicolumn{2}{|c|}{$.242^{* *}$} & \multicolumn{2}{|l|}{.062} & \multicolumn{2}{|l|}{1} \\
\hline & & \multicolumn{2}{|l|}{ SS. } & \multicolumn{2}{|l|}{107.71} & \multicolumn{2}{|l|}{54.837} & \multicolumn{2}{|l|}{-.047} & \multicolumn{2}{|c|}{$.291^{* *}$} & \multicolumn{2}{|l|}{-.096} \\
\hline \multirow[t]{3}{*}{ Socia } & Support & PND. & & 9.7813 & & 5.454 & & 1.000 & & .127 & & .239 & \\
\hline & & & MS. & & 121.7 & & 46.654 & & .127 & & 1.000 & & .095 \\
\hline & & & AA. & & 25.734 & & 11.211 & & .239 & & .095 & & \\
\hline
\end{tabular}

** Correlation is significant at 0.01 level

* Correlation is significant at 0.05 level

a Cells contain zero-order (Pearson) correlations.

KEY:

PND $=$ Postnatal Depression

MS = Marital Stress

$\mathrm{AA}=$ Antenatal Anxiety

SS $=$ Social Support

Table 4.2 showed partial correlations computed between social support scores, marital stress score, antenatal anxiety scores and postnatal depression. This results showed a significant positive relationship between antenatal anxiety and postnatal depression, $r(128)=.242$, $\mathrm{p}<.01$; postnatal depression and social support, $\mathrm{r}(128)=.291, \mathrm{p}<.01$. Another relationship was tested for between these variables controlling for social support and the result showed that antenatal anxiety is significantly related to postnatal depression. Meaning that without social support, the possibility that with antenatal anxiety, postnatal depression will rise is high. This further proved that social support mediates the influence of antenatal anxiety on postnatal depression; hence, hypothesis two is accepted. The result shows the partial influence of social support on.

\section{Hypothesis 3}


There will be a significant correlation among marital stress, antenatal anxiety, social support and postnatal depression among nursing mothers in Ibadan. The hypothesis was tested using Pearson Correlation tool and the result is presented in Table 4.3

Table 4.3: Summary Table showing Correlation Matrix between Marital Stress, Antenatal Anxiety, Social support and Postnatal Depression

\begin{tabular}{|llllcl|}
\hline & & Depression & Anxiety & Social Support & Marital Stress \\
\hline Depression & Pearson Correlation & 1 & $.242\left(^{* *}\right)$ & -.047 & .108 \\
& Sig. (2-tailed) & & .006 & .596 & .226 \\
& $\mathrm{~N}$ & 128 & 128 & 128 & 128 \\
\multirow{5}{*}{ Anxiety } & Pearson Correlation & $.242^{* *}$ & 1 & -.096 & .062 \\
& Sig. (2-tailed) & .006 & & .128 & .485 \\
& $\mathrm{~N}$ & 128 & 128 & 128 & 128 \\
\multirow{5}{*}{ Social Support } & Pearson Correlation & -.047 & -.096 & 1 & $.291^{* *}$ \\
& Sig. (2-tailed) & .596 & .281 & & .001 \\
& $\mathrm{~N}$ & 128 & 128 & & 128 \\
Marital Stress & Pearson Correlation & .108 & .062 & $.291^{* *}$ & 1 \\
& Sig. (2-tailed) & .226 & .485 & .001 & \\
& $\mathrm{~N}$ & 128 & 128 & 128 & 128 \\
\hline
\end{tabular}

** Correlation is significant at the 0.01 level (2-tailed)

From table 4.3, antenatal anxiety has a significant positive correlation with postnatal depression ( $\mathrm{r}=0.242, \mathrm{p}<.05)$; social support has an inverse correlation with postnatal depression $(r=.047)$, although this shows that lack of social support may likely lead to postnatal depression and when social support is available, postnatal depression is not likely; and marital stress has a positive correlation with postnatal depression $(r=.108)$. Therefore hypothesis three was partially supported.

\section{Hypothesis 4}

Marital stress, antenatal anxiety, social support will have significant joint and independent influence on postnatal depression. The hypothesis was tested using multiple regression analysis and the result was presented in Table 4.4 .

Table 4.4: Summary Showing Multiple Regression Analysis of Independent and Joint Influences of Marital Stress, Antenatal Anxiety, and social Support on Postnatal Depression

\begin{tabular}{|c|c|c|c|c|c|c|c|c|}
\hline Dependent & Variables & $\mathrm{R}$ & R2 & $\mathrm{F}$ & $\mathrm{P}$ & $\beta$ & $\mathrm{t}$ & Sig \\
\hline \multicolumn{9}{|l|}{ Variable } \\
\hline & Anxiety & & & & .230 & 2.633 & $<.05$ & \\
\hline Postnatal & Social Support & .265 & .070 & 3.128 & $<.05$ & -.057 & -.629 & n.s \\
\hline Depression & marital Stress & & & & & .110 & 1.212 & n.s \\
\hline
\end{tabular}


Table 4.4 showed that antenatal anxiety has a significant independent influence on postnatal depression $(\beta=230 ; t=2.633 ; \mathrm{P}=<.05)$, meaning that the higher the level of anxiety a mother has during the antenatal period has a significant influence on the onset of anxiety and depression in the postnatal period. More so, there was a significant joint influence of marital stress, antenatal anxiety and social support on postnatal depression $\left(\mathrm{R}^{2}=.070, \mathrm{~F}=3.128\right.$, $\mathrm{P}<.05$ ) with $7 \%$ explanation of the variability of the dependent variable. Therefore, hypothesis four was partially supported.

\section{DISCUSSION OF FINDINGS}

The first hypothesis tested the correlation among marital stress, antenatal anxiety, social support and postnatal depression; and the result revealed that antenatal anxiety and postnatal depression was correlated, also, social support and marital stress. The result; from the tested hypothesis is consistent with the work of Siu et al, (2012) findings, who concluded that anxiety-prone personality, antenatal anxiety and marital dissatisfaction all independently predict postnatal depression. Leigh and Milgrom, (2008) also identified history of depression, antenatal depression, antenatal anxiety, stressful life events, negative cognitive attribution style, low self-esteem, low social support and low income as risk factors strongly associated with postnatal depression. Forman et al., (2000) and Seguin et al., (1999) also found that lack of social support was a strong risk factor for postnatal depressive symptoms. Consequently, O'Hara, Rehm and Campbell (1983) studied social support and found that depression postnatal women reported that their spouse did not provide adequate instrumental and emotional support following delivery.

The second research hypothesis showed that antenatal anxiety has a significant independent influence on postnatal depression among nursing mothers in Ibadan was supported. This was consistent with the findings of Hayworth et al., (1980); Watson et al., (1984) who established a relationship between measured anxiety during pregnancy and the level of postnatal depression. Also, it was supported in the subsequent studies by Johnstone et al. (2001) and Neter et al. (1995) who found that higher levels of anxiety strongly predicted levels of postnatal depressive symptom atology.

O'Hara and Swain (1996) also analyzed the results of 5 studies, comprising nearly 600 subjects and also found that anxiety during pregnancy was a strong-moderate predictor of subsequent depression following childbirth. This finding was supported by Beck (2001) who analyzed the results of 4 studies, a total of 428 subjects, and found anxiety to be a moderate predictor of postnatal depression.

The third hypothesis states that social support will significantly mediate the influence of marital stress and antenatal anxiety on postnatal depression. The hypothesis was supported that social support mediates the influence of antenatal anxiety on postnatal depression. This finding supports the work of Owoeye et al., (2006) which holds that, without social support, the possibility that with antenatal anxiety, postnatal depression will arise is high. Hence, social support mediates the influence of antenatal anxiety on postnatal depression. The third hypothesis was therefore accepted.

The fourth hypothesis stated that age, educational level, marital status, family structure, and job status will have significant joint and independent influence on postnatal depression. The hypothesis was partially supported. The outcome aligned with a research conducted by Swain, (1996) which revealed that age, educational level, marital status, family structure, and job status have always remained major predictors of postnatal depression. 


\section{CONCLUSION AND RECOMMENDATION}

Conclusively, the present study examines marital stress, antenatal anxiety, social support and postnatal depression among nursing mothers in Ibadan. Antenatal anxiety and social support, in their various degrees are significant risk factors, to the exhibition of depressive symptoms among mothers who have a previous history of depression before the postnatal period. The influence of all this variables were examined, although, marital stress has not gained enough attention in the literature in relation to postnatal depression. Conclusions, based on the analysis of the research data, are stated as follow:

n. Antenatal anxiety has a significant positive correlation with postnatal depression among nursing mothers in Ibadan. Social support has an inverse correlation with postnatal depression among nursing mothers in Ibadan. Although, marital stress has correlation with postnatal depression among nursing mothers in Ibadan, but it is not significant.

o. Antenatal anxiety has a significant independent influence on postnatal depression among nursing mothers, while marital stress, antenatal anxiety and social support has a joint influence on postnatal depression among nursing mothers in Ibadan.

p. Showed partial correlation computed between social support scores, marital stress scores, antenatal anxiety scores and postnatal depression.

q. Age, educational level, marital status, family structure, and job status has a significant joint influence on postnatal depression, while only family structure has an independent influence on postnatal depression among nursing mothers in Ibadan.

Understanding the role of a healthy mental and physical health of women in the society in order for the achievement of a good physical, psychological and developmental wellness of their children has been a concern for healthcare professionals in recent time. Mothers are the sole determinant of the wellness of their children in all ramifications, therefore, there is need to ensure that they have a little or no stress, for members of mothers' informal social support network, such as their husbands, partners, their own mother and mother-in-laws, relatives and friends to provide functional social support throughout the pregnancy, delivery and postnatal periods. It is therefore recommended that healthcare professionals in the community primary health centers, should not only screen for anxiety and postnatal depression but also assess the independent and joint risk factors that are related to postnatal depression in pregnant women. A closer monitoring of pregnant women for the risk factors would ensure for an on-time management of such findings.

The first year of a child is very crucial in terms of cognitive, physical and psychological development, but for some of them, that is the period when their mothers are susceptible to developing depressive symptoms, hence, mothers in acting out the symptoms, neglect the care for their babies. Consequently, there is the pertinent need to incorporate programme and psychological interventions for postnatal depression in nursing mothers which will be aimed at reducing the impact of these risk factors on the mothers and their families and this may help to minimize the chance of developed countries have shown that nondirective counseling by health visitors, dynamic psychotherapy (Cooper \& Murray, 1997), cognitive behavioural therapy (CBT), counseling and antidepressants (Appleby, 1997) are all effective treatment for postnatal depression.

\section{References}

Aderibigbe, Y. A., Gureje, O., \& Omigbodun, O. (1993). Postnatal Emotional Disorders in Nigerian Women. A Study of Antecedents and Associations. British Journal of Psychiatry, vol. 163, pp. 645-650 
Adewuya A.O., Adekunle B. E., \& Adejare M. L. (2005). Prevalence of Postnatal Depression in Western Nigerian Women: a Controlled Study: International Journal of Psychiatry in Clinical Practice; 2005, Vol. 9, No. 1, Pages 6064

Adewuya et al (2005). Socio-Demographic and Obstetric Risk Factors for Postpartum Depressive Symptoms in Nigerian Women. Journal of Psychiatric Practice, vol. 11-Issue 5:pp 353-358

Adewuya., O.A. (2006). Postnatal Depression in Primary Care Population in Nigeria. Gen Hosp Psychiatry 2006; 28:133-6

Appleby L, Warner R. W., Whitton A.L., Faragher B. (1997). A Controlled Trial of Flouxetine and CognitiveBehavioural Counseling in the Treatment of Postnatal Depression. Br Med J 314: 932-936

Areskog, B., Uddenberg, N., Kjessler, B., (1981). Fear of Childbirth in Late Pregnancy. Gynecol. Obstet. Invest. 12, 262-266.

Beck, N.C., Siegel, L.J., Davidson, N.P., Kormeier, S., Breitenstein, A., Hall, D.G., (1980). The Prediction of Pregnancy Outcome: Maternal Preparation, Anxiety and Attitudinal Sets. J. Psychosom. Res. 24, 343-351.

American Psychiatric Association (1994). Diagnostic and Statistical Manual of Mental Disorders, $4^{\text {th }}$ Edition. Washington, DC.: American Psychiatric Association

Armstrong, D., Hutti, M., (1998). Pregnancy after Prenatal Loss: the Relationship Between Anxiety and Prenatal Attachment in a Subsequent Pregnancy. J. Obstet. Gynecol. Neonatal Nurs. 27, 183-189

Beck, A.T. (1983). Cognitive Theory of Depression: New Perspectives. In P.J. Clayton \& J.E. Barrett (Eds.), Treatment of Depression: Old Controversies and New Approaches. (pp. 265-288). New York, NY: Raven Press.

Beck C.T. (2001). Predictors of Postpartum Depression: an Update: Nursing Research, 50, 275-285

Bowlby, J., 1973. Attachment and Loss: Separation, vol. 2. Basic, New York.

Chan S. \& Levy V. (2004). Postnatal Depression: a Qualitative Study of the Experiences of a Group of Hong Kong Chinese Women. Journal of Clinical Nursing 13, 120-123.

Commission on the Family (1998). Strengthening Families for Life: Final Report to the Minister for Social and Community and Family Affairs. Dublin: Government Publications.

Cooper P.J., \& Murray L. (1997). The Impact of Psychological Treatments of Postpartum Depression on Maternal Mood and Infant Development. In: Murray L, Cooper PJ (eds), Postpartum Depression and Child Development. Guildford Press, London, 201-220

Da Costa, D., Larouche, J., Dritsa, M., Brender, w., (1999). Variations in Stress levels Over the Course of Pregnancy: Factors Associated with Elevated Hassles, State Anxiety and Pregnancy - Specific Stress. J. Psychosom. Res. 47, 609621.

Ege E. Timur S, Zincir H. Gec, Kil E. \& Sunar-Reeder B. (2008) Social Support and Symptoms of Postpartum Depression among New Mothers in Eastern Turkey. Journal of Obstetric Gynaecologic Research 34, 585-593

Evans J, Heron J. Francomocomb H. Okes \& golding J. (2001): Cohort Study of Depressed Mood During Pregnancy and after Childbirth. British Medical Journal 323, 257 - 260

Elliot S.A., Gerrad J., Ashton C., Cox J.L. (2000). Training Health Visitors to Reduce Levels of Depression after Childbirth. An Evaluation. J. Ment Health 10: 613-625

Forman, D.N. Videbech, P., Hedegaard, M. Salvig, J. D., \& Secher, N. J. (2000). Postpartum Depression: Identification of Women at Risk. British Journal of Obstetrics \& Gynaecology , 107, 1210-1217.

Gao, L., Chan, S.W., \& Mao, Q. (2009). Depression, Perceived Stress and Social Support among First-time Mothers and Fathers. Research in Nursing \& Health, 32(1), 50-58. Doi: 10.1002/nur.20306.

Ghubash Postnatal Depression Scale, Social Psychiatry \& Psychiatric Epidemiology, 32(8), 474-476, R., \& AbouSaleh, M.T. (1997). Postpartum Psychiatric Illness in Arab Culture: Prevalence and Psychosocial Correlates. [see comments]. British Journal of Psuychiatry, 171, 65-68

Ghubash, R. Abou-Saleh, M.T., \& Daradkeh, T.K. (1997). The Validity of the Arabic Edinburgh 23 (2), 11-17

Glasser S. Barell V. Boyko V. Ziv A. Lusky A \& AIS (2000) Postpartum Depression in an Israeli Cohort: Demographic Psychosocial and Medical Risk Factors. Journal of Psychosomatic Obstetrics and Gynaecology 21, 99-108.

Green K. Broome H. Mirabella J. (2006). Postnatal Depression among Mothers in the United Arab Emirates: SocioCultural and Physical Factors. Psychological Health and Med. 11(4): 425-431. 
Haggman-Laitila, A. (2003). Early Support Needs of Finish Families with Small Children. Journal of Advanced Nursing, 298, 223-226

Haggman-Laitila A. (2003) Early Support Needs of Finish Families with Small Children. Journal of Advanced Nursing 41, 595-606

Hayworth, J., Little, B.C. Carter, S.B. Raptopoulous, P., Priest, R. G., \& Sandler, M. (1980). A Predictive Study of PostPartum Depression: Some Predisposing Characteristics. Br. J. Med. Psychol., 53, 161-167.

Higgins, P., Murray, M.L., Williams, E.M., (1994). Self-Esteem, Social Support, and Satisfaction. British Medical Journal 323, $257-260$

Huizink, A.C. Mulder, E.J., Robles De Medina, P.G., Visser, G.H., Buitelaar, J.K., (2004). Is Pregnancy Anxiety a Distinctive Syndrome. Early Hum. Dev, 79, 81-91.

Inandi T, Elci O, Ozturk A, Egri M, Polat A. \& Sahin T. (2002) Risk Factors for Depression in Postnatal First Year, in Eastern Turkey. International Journal of Epidemiology 31 (doi:10.1093/ijie/31.6.1201), 1201-1207.

Johnstone, S.J., Boyce, P.M. Hickey, A.R., Morris-Yatees, A.D. \& Harris, M.G. (2001). Obstetric Risk Factors for Postnatal Depression in Urban and Rural Community Samples. Australian and New Zealand Journal of Psychiatry, $35,69-74$

Kalil, K.M. Gruber, J.E., Conley, J., Syntiac, M., (1993). Social and Family Pressures on Anxiety and Stress During Pregnancy, J. Prenat. Perinat. Psycho. 8, 113-118.

Kaplan H, Sadock V, James B. (2009). The Summary of Psychiatry, Translated by Rezaie, Farzin, Tehran: Arjmand Publication, $3^{\text {rd }}$ Edition.

Kendell R.E., Chalmers J.C. Platz C. (1987). Epidemiology of Puerperal Psychoses. British Journal of. Psychiatry. 150:662-673.

Lee DTS, Yip ASK, Leung TYS, Chung TKH (2004): Ethnoepidemilogy of postnatal depression: Prospective Multivariate Study of Socio-Cultural Risk Factors in a Chinese Population in Hong Kong. Br J. Psychiatry 2004, 184:34-40

Lee, D.T., Yip, A.S.K., Chiu, H.F.K., Leung, T.Y.S., \& Chung, T.K.H. (2001). Screening for Postnatal Depression: Are Specific Instruments Mandatory. Journal of Affective Disorders, 63(1-3), 233-238

Leahy-Warren P \& McCarthy G. (2007). Postnatal Depression: Prevalence, Mothers' Perspectives and Treatments. Archives of Psychiatric Nursing 21, 91-100.

Logsdon M. \& Davis D. (2003) Social and Professional Support for Pregnant and Parenting Women. MCN. American Journal of Maternal Child Nursing 28, 371-376.

Melender, H.L., (2002). Experiences of Fears Associated with Pregnancy and Childbirth: A Study of 329 Pregnant Women. Birth 29, 101-111.

Mcveigh, C., Smith, M., (2000). A Comparison of Adult and Teenage Mother's Self-Esteem and Satisfaction with Social Support. Midwifery Report 16, 269-276.

Murray C., \& Lopez A. (1990). The Global Burden of Disease: A Comprehensive Assessment of Mortality and Disability from Diseases, Injuries, and Risk factors in 1990. Harvard School of Public Health on Behalf of the World Bank, Boston, Mass, USA, 1996.

Munk-Olsen T., Laursen T. M., Pedersen C. B., Mors O., \& Mortensen P. B. (2006) New Parents and Mental Disorders: A Population-Based Register Study. JAMA, 296:2582-2589

Neter, E. Collins, N.L., Lobel, M., \& Dunkel-Schetter, C. (1995). Pshychosocial Predictors of Postpartum Depressed Mood in Socioeconomically Disadvantaged Women. Women's Health, 1, 51-75.

Nhiwatiwa, S., Patel, V., \& Acuda, W., (1998). Predicting Postnatal Mental Disorder with a Screening Questionnaire: a Prospective Cohort Study from Zimbabwe, Journal of Epidemiology and Community Health, vol. 52, no. 4, pp. 262-266

Nicolson, P. (1990). Understanding Postnatal Depression: A Mother-Centered Approach. J Adv. Nurs., 15, 689695

O’Hara, M.W., Rehm, L.P., \& Campbell, S.B. (1983). Postpartum Depression. A Role for Social Network and Life Stress Variables. J.Nerv. Ment. Dis., 171, 336-341. 
O’Hara, M.W. \& Swain, A.M. (1996). Rates and Risk of Postpartum Depression-a Meta-Analysis. International Review of Psychiatry, 8, 37-54.

Omoluabi, P.F. (1994). Psychosocial Causes and Remedies of Single Parenthood. Paper Presented at the First APQUEN Conference, Enugu.

Owuoeye A.O. et al., (2006). Risk Factors of Postpartum Depression and EPDS Scores in a Group of Nigerian Women. Paper Presented at the First APQUEN Conference, Enugu.

Paarlberg, K.M., Vingerhoets, A.J., Passchier, J., Dekker, G.A., Heinen, A.G., Van Geijn, H.P., (1999). Psychosocial Predictors of Low Birth Weight: a Prospective Study. Br. J. Obstet. Gynaecol. 106, 834-841.

Patel, V., Rodrigues, M., \& DeSouza, N. (2002). Gender, Poverty, and Postnatal Depression: a Study of Mothers in Goa, India. American Journal of Psychiatry, 159, 43-47

Rahman, A., Iqbal, Z., \& Harrington, R. (2003). Life Events, Social Support and Depression in Childbirth: Perspectives from a Rural Community in the Developing World. Psychological Medicine, 33(7), 1161-1167

Raphael-Leff, J., (2005). Psychological Processes of Childbearing. The Anna Freud Centre, London.

Robertson, E., Grace, S., Wallington, T., Stewart, D.E. (2004). Antenatal Risk Factors for Postpartum Depression: a Synthesis of Recent Literature. Gen. Hosp. Psychiatry 26, 289-295.

Robinson, G.E. \& Stewart, D.E. (2001). Postpartum disorders. In N.L. Stotland \& D.E. Stewart (Eds.), Psychological Aspects of Women's Health Care (2nd ed. Ed., pp. 177-139). Washington, DC: American Psychiatric Press, Inc.

Rizzardo, R., Magni, G., Andreoli, C., Merlin, G., Andreoli, F., Fabbris, L., (1985). Psychological Aspects During Pregnancy and Obstetrical Complications. J. Psychosom. Obstet. Gynecol. 4, 11-22.

Saisto, T., Halmesmaki, E., (2003). Fear of childbirth: a neglected dilemma. Acta. Obstet. Gynecol. Scand 82, 201208.

Saisto, T., Salmela-Aro, K., Nurmi, J.E., Halmesmaki, E., (2001). Psychosocial Characteristics of Women and their Partners Fearing Vaginal Childbirth. Bjog 108, 492-498.

Schachman KA, Lee RK \& Lederman RP, (2004) Baby Boot Camp: Facilitating Maternal Role Adaptation Among Military Wives. Nursing Research 53, 107-115.

Scradis D.A. (2005): Normalizing Postpartum Depressive Symptoms with Social Support. Journal of the American Psychiatric Nurses Association 11, 223-230

Seguin, L., Potvin, L., St Denis, M., \& Loiselle, J. (1999). Depressive Symptoms in the Late Postpartum Among Low Socioeconomic Status Women. Birth, 26, 157-163.

Sjogren, B., (1997). Reasons for Anxiety About Childbirth in 100 Pregnant Women. J. Psychosom. Obstet. Gynaaecol. 18, 266-272.

Siu et al., (2012). Antenatal Risk Factors for Postnatal Depression: a Prospective Study of Chinese Women at Maternal and Child Health Centers. BMC Psychiatry 12:22

Stewart D., Robertson E., Dennis C.L. Grace S.L., \& Wallington T. (2003). Postpartum Depression: Literature Review of Risk Factors and Intervention, Public Health Advisory Committee, Toronto, Canada.

Surkan P. Peterson K., Hughes, M. \& Gottlieb, B., (2006). The Role of Social Networks and Support in Postpartum Women's Depression: a Multiethnic Urban Sample. Journal of Maternal and Child Health Journal 10 (4), $375-383$.

Tenant, C. (2001). Work Related Stress and Depressive Disorders. Journal of Psychosomatic Research, 51, $697-704$. 